Vol. 6, No. 2, 2019

https://doi.org/10.23939/eem2019.02.066

UDC 658.5.011:004.01 JEL Classification Gode C89

\author{
V. Shkvir \\ Lviv Polytechnic National University, Ukraine, PhD, Associate Professor \\ E-mail: shkvir@ukr.net
}

I. Borshchuk
Lviv Polytechnic National University, Ukraine, PhD, Associate Professor

\title{
THE SPECIFICS OF DESIGNING INFORMATIONAL DOCUMENTS OF NONAUTHOMATED DATABASE OF THE COMPUTER ACCOUNTING SYSTEM
}

\begin{abstract}
Theoretical aspects of designing informational documents of nonauthomated database of computer accounting system (CIS-BO) are clarified. At the same time, the main emphasis is on such components of nonautomated database, as information documents with operational and resultant information, because for machine processing of data their proper construction defines the efficient operation of CIS-BO.The conditions of functioning CIS primary documents remain the leading carriers of input (primary) data and a means of registration performed by enterprises or establishments toward economic operations. Despite current trends in the use of paperless informational technology, the document is still the most widespread carrier of information.There is a technique of designing forms of operational information, taking into account the peculiarities of the application of different methods of controlling the correctness of informational input. Also, there are works on creating visual forms of information output.

Key words: computer accounting informational system, informational software, nonauthomated database, automated database, methodology for designing primary documents, work with creating visual forms of information output.
\end{abstract}

\section{Formulation of the problem}

There are many options for creating computer accounting informational systems. Computer specialists develop an automated data base of suchs ystems, but the question of designing the nonautomated data base of such a system is still actual. It is specially true for informational documents with operative information and information about results. The primary documents for sales, that enterprises and organizations use, in the vast majority donot take into account the specifics of their work. The accountant needs to cross out the unnecessary lines and columns of such documents to exclude any possibility of illegal actions in the future (writing in the documents of non-existent material as sets in the warehouse, fictitious production of products by the employee, etc.).A thoughtful designed primary document, especially for the conditions of machine information processing, dramatically improves the efficiency of using CIS-BO.

Also, purchasing software for accounting automation, the buyer chooses a specific list and content of documents with results. But many of these productive forms do not suit the buyer, do not contain the complete information needed to make effective management decisions. Such forms need to be modified and must be designed for the specific nature of the enterprise or organization.

Based on practical experience in the development CIS-BO for budget organizations, machine-building enterprises, exploration expeditions, etc. we are deeply convinced that accountants have the best knowledge of the subject area, and only they understand which information and in which extent should be shown in primary and output documents of enterprise. First of all, accounting staff should 
develop informational materials for nonautomated IB KIS-BO, because they will operate this system, and accordingly, the theoretical and practical aspects of designing such documents should be shown in specific guidelines for employees of accounting services in enterprises and organizations.

\section{Analysis of the latest researches and publications}

In [1], the authors made an overview of works - monographs, educational textbooks and manuals, scientific articles - devoted to the issues of implementation informational systems and technologies in accounting. Several aspects in building computer accounting systems have not been disclosed at all, or are referred superficially in scientific work. This concerns, first of all, the issues of building a nonautomated database of CISBO and, in particular, the design of informational documents of nonautomated database. Thus, the author of the monograph [3, p. 134] considers the improvement of commercial information carriers in CIS-BO but does not show the peculiarities of their design, especially taking into account the methods of controlling the correctness of the input of information, etc. aspects. The monographs [4,5] make no mention in aspects of building the nonautomated database, although the author considers the audit in the context of the use of computer accounting systems. In scientific articles, the authors, covering the issues of application of informational systems and technologies in accounting, donot even mention the peculiarities of designing information documents of the nonautomated database CIS-BO. To some extent, such issues have been reflected in several text books [6, 7, 8, 9], but quite superficially. Therefore, the problems of designing a nonautomated database o finformational documents requires more detailed study.

The purpose of the article - to develop the methods of designing documents of the nonautomated database KIS-BO, that accountants will use and show its practical implementation.

\section{The presentation of the main material}

In [1], the authors considered the methodology of designed codes that existed in the nomenclature as an existing component, fixed in the system of informational and exploratory system, based on a computerized system of accounting survey and subjects that were presented by separate methods, developed a methodology for designing informational data, necessary for this. For performing in hole amount accounting functions in management of the enterprise and for preparing the reports provided to external users, it is necessary to collect, register, transmit, accumulate, store and process credentials, which in turn requires the implementation of this informational process, the availability of the necessary forms of work organization, technical means, methods and ways of data transformation, as well as staff of specific qualifications. All of this makes an automated accounting information system, which is an integral part of the CIS (AIS) of the enterprise.

Through KIS-BO's security components, as it is known [1, 2], are informational and methodological materials, a classification and coding system, and a database (IB), which in turn contains both nonauthomated and authomated IB.

The structure of the nonauthomated IB KISBO is shown in Fig. 1.

Based on the purpose of the article, we are interested in informational documents with operational and based on results information, since their correct construction ultimately depends on the effectiveness of CIS-BO, regardless of whether the company purchased this system in the software market, or develops its own.

Own practical experience of developing CISBO for budget organizations, machine-building enterprises, etc. allows us to assert that accountants are best in the subject area and only they understand what the content of the primary documents in the accounting areas should be in content and what resultant information in the source machine charts most fully reflects the essence of the accounting processes. Therefore, information documents with operational and based on results information for nonauthomated IB KIS-BO should, in our opinion, be developed by the accountants who will operate this system. Therefore, accountants should have a deeper theoretical knowledge and practical aspects of such work. 


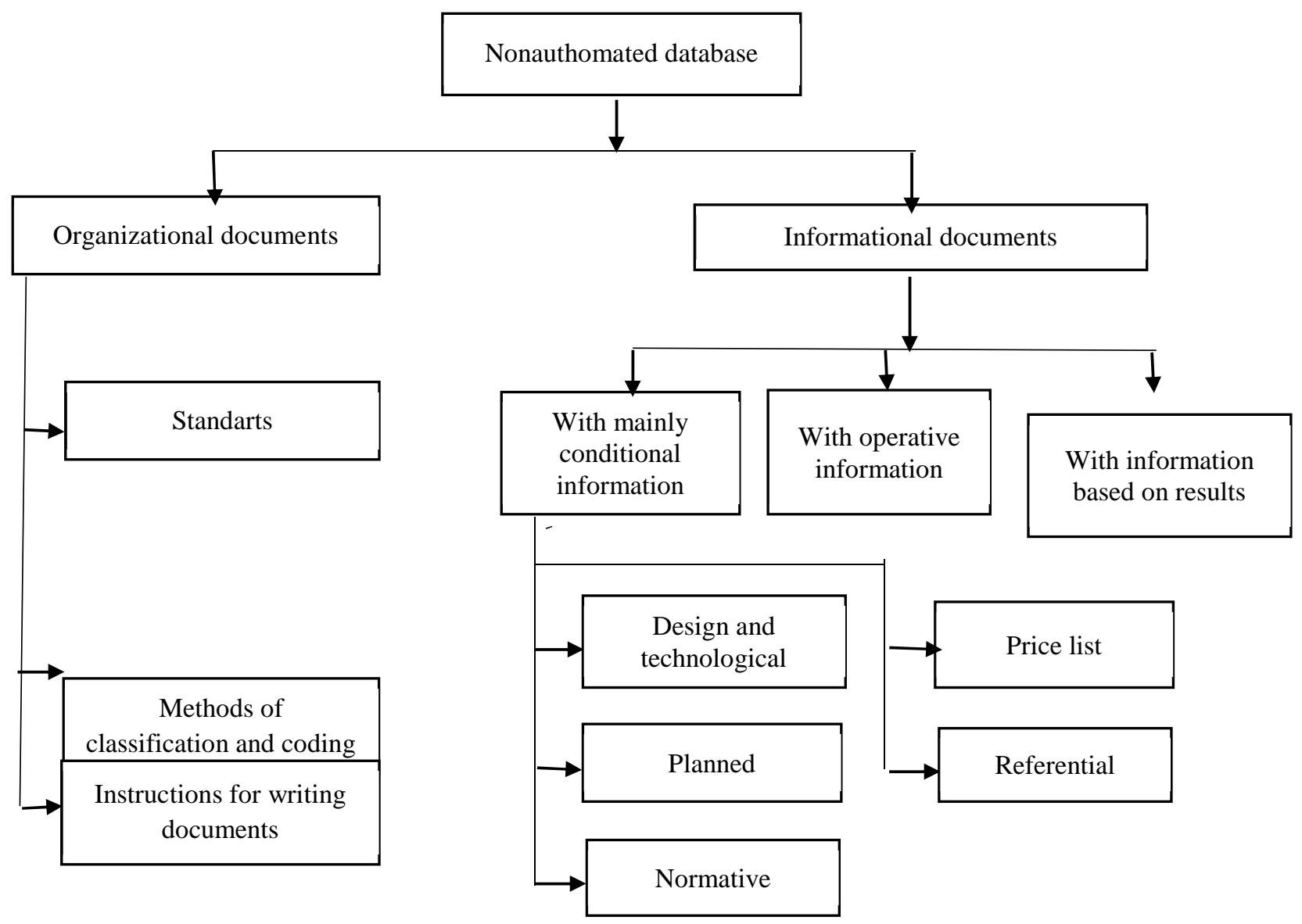

Fig. 1. Structure of nonauthomated database

In order to consider the question of development informational messages about work, CIS-BO IB adheres to certain basic concepts that need to be noted in such questions.

In the functioning IC are the original documents that were based on the most recent (primary) data received from the service, which were recorded in their own enterprises. Not using current trends, using "paperless" information technology, the document is the most widespread in new information.

There are some problems when designing forms of input and output documents. In our opinion, the most important are two, in particular:

1) designing the content of the documents, the composition of the details and indicators that will be included in these documents;

2) designing the geometry of documents, that is, placing details in the form of documents.

In conclusion, from the successful resolution of the first problem depends the effectiveness of management decisions based on the resulting CIS-
BO information. The documents should necessarily have all the details are required to compile a complete set of accounting records, control and analysis of business activities. Primary documents are the basis of accounting, and are a means of prompt action, guidance and control over the course of the production process. In addition, primary documents are a kind of link between contractors and company management.

For example, a piecework contract is a task for the contractor and is intended for operational planning, the link between the contractor and the work manager, is controlled and signed by him (master, foreman, etc.). Once the work has been completed, the outfit is the basis for accounting the implementation of the plan, the determination of labor productivity, the calculation of wages, as well as for the distribution of wages in the direction of production costs and performs a number of other functions.

Material values accept and release based on primary documents od these values.; carry out 
quantitative and summative accounting in warehouses and in bookkeeping, writing off the amounts of value of tangible assets in the directions of production costs for making it; prompt accounting in the logistics department of the enterprise; compile statistical reports and the like.

Therefore, when designing primary documents, it is necessary to take into account the requests of all business units that use the input data recorded in these documents.

Thinking about the second problem of designing informational documents - creating their geometry - let's clarify some familiar concepts, including:

- forms of primary documents;

- a model of document construction;

- the technique of designing the primary material.

As is known [2], there are three forms of initial construction of the documents: questionnaires, linear, tabular (plate), combined.

The questionnaire form of construction involves the placement of machine-requisite details in a vertical sequence. For the typed names of the details left side of each line is used, and the right hand is used for hand answers to the questions. This form can be used if the primary documents are filled by different persons. According to the questionnaire method, identity cards of employees, some zones of statistical reporting forms were constructed.

An example of constructing a document in a questionnaire way is given below.

\begin{tabular}{|l|l|}
\hline \multicolumn{1}{|c|}{ Name of the details } & Meaning of details \\
\hline $\begin{array}{l}\text { Place of work (direstion, } \\
\text { department) }\end{array}$ & \\
\hline Basic number & \\
\hline $\begin{array}{l}\text { Surname, name and middle } \\
\text { name }\end{array}$ & \\
\hline
\end{tabular}

The linear form of construction involves dividing the blank into zones for recording separate groups of logical or arithmetic dependencies. At the same time, it is filled by one artist and belonging to one particular accounting work or having another form of connection. In this form, there are two columns for each prop: one for the name and the other for the data recording. Forms built on a linear basis are common in accounting work. They can include all single-line documents, such as individual outfits, income and expense documents for accounting for tangible assets, etc.

An example of constructing a document in a linear way is given below.

\begin{tabular}{|c|c|c|c|c|c|}
\hline \multicolumn{2}{|c|}{ Department } & \multicolumn{2}{c|}{ Field } & \multicolumn{2}{c|}{ Executer } \\
\hline Name & Code & Name & Code & $\begin{array}{c}\text { Surname, } \\
\text { initials }\end{array}$ & $\begin{array}{c}\text { Basic } \\
\text { number }\end{array}$ \\
\hline & & & & & \\
\hline
\end{tabular}

A spreadsheet or tabular form of construction provides several rows for each zone or group of details. This principle of creation comes from a linear structure. The advantages of this form are the compact placement of details and the ability to capture a larger amount of information than in other forms. It reduces the total number of primary documents in the enterprise.

Below you can see an example of constructing a document in a tabular way.

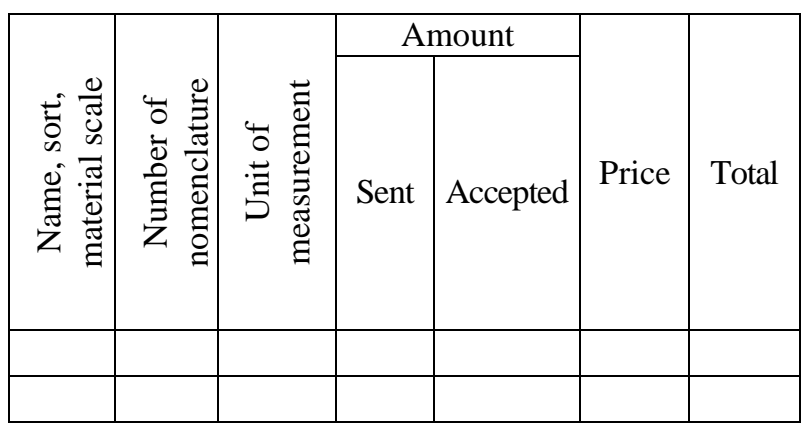

Documents that combine different forms, such as linear and tabular, linear and questionnaire, etc., are more common. Therefore, the most effective is the combined form, in which part of the details is in a linear form, and the other part is in a report card and questionnaire (for example, a card for the production of workers, etc.). Combined form fully connects the benefits of different principles of form building.

As an example of a document designed for a combined form of construction, give a type of invoice for the delivery of finished products (Fig. 2).

Invoice №

\begin{tabular}{|c|c|l|c|}
\hline Date & $\begin{array}{c}\text { Type of } \\
\text { operation }\end{array}$ & $\begin{array}{l}\text { Warehouse- } \\
\text { receiver }\end{array}$ & $\begin{array}{c}\text { Department- } \\
\text { sender }\end{array}$ \\
\hline & & & \\
\hline
\end{tabular}




\section{Shkvir, I. Borshchuk}

Who is the receiver of material (Surname, name, middle name)

\begin{tabular}{|c|c|c|c|c|c|c|}
\hline \multirow{2}{*}{$\begin{array}{c}\text { Name, sort, } \\
\text { material scale } \\
\text { матеріалу }\end{array}$} & \multirow{2}{*}{$\begin{array}{c}\text { Number of } \\
\text { nomenclature }\end{array}$} & \multirow{2}{*}{$\begin{array}{c}\text { Unit of } \\
\text { measurement }\end{array}$} & \multicolumn{2}{|c|}{ Amount } & \multirow[b]{2}{*}{ Price } & \multirow[b]{2}{*}{ Total } \\
\hline & & & Sent & Accepted & & \\
\hline & & & & & & \\
\hline & & & & & & \\
\hline
\end{tabular}

Handed over

Acccepted

Fig. 2. Form of nomenclature for delivery of finished products

Documents that reproduce the processes of operating in structural units of management are different in purpose and divided into estimates, designed and technological, planned, regulatory, accounting, operative, and more. Such grouping allows determining the sources of origin of each type of documentation, routes of their movement, organizational bases of development, tools, and methods of processing.

Despite the wide variety of unified forms of primary documents, unique (own) forms of internal documentation are developed for specific information processing systems that satisfy certain specific user conditions. Such forms shall be designed in accordance with the requirements of the standards.

The primary document contains a definite composition of detail-signs, referential and grouping, detail-basics, input, and output. On the document form, the details are following the rules that require the unified documentation system and the requirements of standardization of documents.

The standard forms the formats and sizes of the document fields and rules for the placement of details, taking into account the sample form. A sample form is a model for building a document (Fig. 3).

\begin{tabular}{|c|c|}
\hline $\begin{array}{c}\text { Adress and name of } \\
\text { company }\end{array}$ & $\begin{array}{c}\text { Index of document and } \\
\text { approval stamp }\end{array}$ \\
\cline { 2 - 2 } & $\begin{array}{c}\text { Name and meaning of } \\
\text { details-signs, regular on } \\
\text { document }\end{array}$ \\
\hline \multicolumn{2}{|c|}{ Name of document and his number } \\
Zone of content (name of the rows, columns and \\
meaning of details)
\end{tabular}

Fig. 3. Model of making document
Each document divides into six zones. The first four zones are the title part of the text, the fifth zone is the informative part, and the sixth zone is the legal part.

Forms of primary documents should be as much as possible adapted for machine processing of information and convenient for human perception. First of all, it is necessary to take into account the logical sequence of placement of details, ease of filling, reading, and processing. It is advisable to place the information on the document in the following order: constant, then variable referential and grouping signs, and detail-basics.

A requirement is also to minimize the details of the document. It is not required to make regulatory, pricing, referential, as well as secondary data, which significantly simplifies the forms of materials, dramatically facilitates their completion and further processing, improves the reliability of the information, reduces the time spent on the preparation of arrays and their control. Usually in primary documents enters unique columns and rows to record the control numbers to control the completion of documents, transfer of data to machine carrier, and input to EOM. The accountant must have minimal knowledge of methods of controlling the correctness of transferring information from primary documents to the computer to understand the need for designing unique columns and rows in materials to record the control numbers. So let's look at this more detailed.

Designing processes of controlling the correctness of filling and transferring data from primary documents [2, p. 74-77] is connected with the knowledge of methods of ensuring the reliability of the information in the economic informational system.

Most of the control methods based on the introduction and use of excess digits, details, records. You can apply double and usual excess. 
Excess bits calculates according to a specific algorithm for converting values of a controlled number and recorded together with a controlled number. An example of this method is module control. Excess details are a function of manipulating a set of controlled details. The summation is preferably used - the received checksum records in a unique column for this.

Excess records contain control information regarding the block of notations or files in general (for example, balance control).

Double redundancy forms during second transferring of data to machine carrier with subsequent comparison of results. Usual redundancy is on reasonably foreseeable values of controlled details. These include module control and checksum.

Module control. To calculate the control discharge is widely used methods of control module $9,10,11,13$. Firstly determines the sum of $\mathrm{S}$ bits of code (the amount of the products Ki obtained after multiplying each digit Pi by its weight, or the serial number $\mathrm{Ni}$ in the system, $\mathrm{Ki}=\mathrm{Pi}^{*} \mathrm{Ni}$ ). Then sum divides by the selected module $\mathrm{m}$. The resulting residual $d$ subtracts from a division from the same module. The resulting difference $\mathrm{R}=\mathrm{m}-\mathrm{d}$ (or its lower digit) in the form of a control digit is right from the code.

Example. Calculate the control digit number 24856 modul 9

$$
\begin{aligned}
& \mathrm{S}=2 * 5+4 * 4+8 * 3+5 * 2+6 * 1=66 \\
& \mathrm{~S} / \mathrm{m}=66 / 9=7(3), \mathrm{d}=3 \\
& \mathrm{R}=\mathrm{m}-\mathrm{d}=9-3=6
\end{aligned}
$$

Therefore, the number with the check digit 248566. When entering such codes in the computer programmatically, the necessary checks perform and an error will be detected (or not), if any.

If such method of control is used in CIS-BO, when making codes, such as 5-digit number plates, the code length will increase to 6 characters and, accordingly, in the original document of the "Number plate" should have sufficient width to record such details.

The checksum can organize through the line or column of the document. The checksum - is the sum of all the digital details in the control sequence. Determine it before transferring the data to the machine manually using calculators. Examples include finding checksums for the following document:

\begin{tabular}{|c|c|c|c|c|}
\hline Department & $\begin{array}{c}\text { Number } \\
\text { plate }\end{array}$ & $\begin{array}{c}\text { Code } \\
\text { of } \\
\text { detail }\end{array}$ & Amount & Checksum \\
\hline 01 & 1000 & 202 & 30 & 1233 \\
\hline 01 & 1000 & 103 & 10 & 1114 \\
\hline 01 & 1000 & 301 & 20 & 1322 \\
\hline
\end{tabular}

After transferring data to the machine carrier, the checksum is again calculated, but with the help of the program. The failure of the checksums, calculated manually and automatically, indicates an incorrect line.

If the described method of control is used in CIS-BO, the accountant must design a graph for noting the checksums when making primary documents.

Using the checksum on a document column, you can similarly detect the location of an error. Quite often, the accounting notes use the excess files that characterize the document as a whole. Such methods include balance control. Let's say you need to provide the user with the following content:

\begin{tabular}{|c|c|c|c|c|}
\hline $\begin{array}{c}\text { Surname, } \\
\text { name, } \\
\text { middle } \\
\text { name }\end{array}$ & $\begin{array}{c}\text { Number } \\
\text { Plate }\end{array}$ & Salary & Receive & $\begin{array}{c}\text { Total } \\
\text { receiving } \\
\text { per } \\
\text { persont }\end{array}$ \\
\hline A & 100 & 300.00 & 102.00 & 198.00 \\
\hline B & 101 & 105.00 & 12.50 & 92.50 \\
\hline C & 102 & 176.50 & 19.25 & 157.25 \\
\hline & & 581.50 & 133.75 & 447.75 \\
\hline
\end{tabular}

The control is to calculate and compare the amounts:

$581.50-133.75=447.75$

Methods based on usual redundancy include:

- boundary check method (fork method);

- method of reference;

- method of checking the structure of the code;

- method of checking sums and products. 


\section{Shkvir, I. Borshchuk}

A boundary check method is possible if the set of allowable values of the controllable props is within some bounds of the prohibited values.

\section{Amin $\leq \mathrm{A} \leq \mathrm{Amax}$}

Suppose that the value of the props "warehouse code" is in the range from 1 to 12 . Then the control is organized using the looking rule: $1 \leq$ warehouse code $\leq 12$.

The method is sufficient if the values of the controlled props are evenly spaced on the numerical axis.

The method of reference is based on specially created tables that contain the correct requisition codes (for example, vendor codes, employee ID codes, etc.). During the control, the reference table is used to find the controlled code. If such a code is found, the error is considered missing.

Look at an example. The primary documents of the "Sheet of Account a working time" provide information on each employee (each number plate) about the time worked on calculating salary. When from the primary document the accountant who conducts calculations about salary dials the number of number plate, program, in which the information leads in (implements the control of the input of the data by the directory method) goes to the directory with the information about employees. The code from the original document number plate is matched alternately with all the plate numbers in the register before (or not) these codes match. In the first case, the information collected from the primary documents saves in the computer. In the second case (if the number plates do not match) - the error message will be displayed on the monitor screen. In this case, the following actions of the operator (accountant) are possible:

1) the wrong code number plate was typed; you need to correct the error and repeat the input;

2) the correct number plate number has been typed, but the information about this employee is not present in advance in the employee manual. It is necessary to supplement the directory with information about the new employee, so repeat the data from the original documents "Sheet of account the working time."
From the example, we can conclude that updating of directories (before the task is solved) is a prerequisite for controlling the entry of information by the method of the directory.

There are other methods for controlling the correct entry of information into your computers, such as the code structure check method, the sum and product check method, and more. The essence of these methods is in detail in [2].

Today, there are software systems that provide entry and control of data. For the most part, these packages control the format of the props, the presence of forbidden characters, the values of excess bits, the range of signification, the nomenclature of significance by reference, the total sums.

All methods of control of the reliability of information are exclusively programmatically. The same techniques that do not require this are done manually according to the instructions - for example, control of correctness of filling of primary documents.

When thinking about the construction of the primary document, the details that are transferred from the primary material for further processing by CIS-BO should be concentrated in one part of the report and surrounded by a thickened line. Do not move to machine carrier and are not surrounded by a thickened line on the primary document details that can be found in the process of machine processing of information from the referential arrays.

Example 1. From the original document "Invoice from tangibles" does not transfer to the computer the name of the material, the price of its unit, the name of the group of measure, etc., because these details can be selected by the nomenclature number of content from the pre-formed directory of names and prices of tangibles. Accordingly, on the original document "Invoice for the receipt of tangible assets" such details as the name of the material, the price of a unit of material, the name of the group of measure, etc. do not encircle by thickened line.

Example 2. If a primary document from accruing salary is processed, for example, a sheet of account the working time, it is not transferred to the 
computer from the document the name, surname and middle name of the employee, since the nameplate gives the last name, first name and middle name will be found and selected from a pre-generated directory. Therefore, even in the original document "Sheet of account the working time" the name, surname and middle name are not bolded.

It is advisable to carry out the design of primary documents in the following sequence (the technique of designing primary documents):

- determine the content of the original document, the composition of included details;

- to place details in a particular sequence and interconnection;

- develop a sketch of the primary document form (full-scale design);

- unify the types of primary documents;

- agree with the format of the original document with the content of the machine media;

- clarify the form of the original document;

- make a sample document for ordering in a printing house.

If technical means take part in making the primary document, particulars of such factors need to be taken into account. Materials from which data is transmitted by fax, telegraph (they have entered service marks) have certain features.

The size of the blank is determined by the amount of information in this document. The width of each column depends on the maximum number of digits recorded in that column. Abbreviations are used to record textual information. Formulas for calculating the size of the primary document are given in [2, p. 89]

The found width and length values select the appropriate format according to the standard (in the pulp industry produce paper rolls of appropriate sizes) to adjust the width and length of the individual columns and rows of the document. Usually the following standard formats are mm: 420 × 297; 297 x 210; 210 x 148. From a specified sketch, a sample document becomes ready for approving a form and printing.

The design of inference information about results has a lot in common with the design of primary documents, especially in determining storages, a sequence of placement of details. At the same time, design characterizes by some specific requirements, like operational capabilities of the technical means, general data processing technology, purpose and methods of their use.

All output forms divide into two groups:

- intended for visual use;

- designed for machine use.

The first group includes paper documents (machine diagram, diagrams, graphs), a board, a television screen. The second is all machine carriers.

Works in designing visual forms of output makes in the following sequence in:

- determining the list of data with results;

- dividing the result indicators by machine diagram, and video diagram, compiling a list of source forms;

- giving each form a name and number (code);

- determining the frequency of assembly and the time of receipt of each initial form;

- determininging the location of the typescripts and the required number of copies;

- developing a sketch of the original form;

- determining the composition of the informational arrays required to obtain each form;

- establishing the sequence of making the initial forms and the general technological process; preparing reference examples of the initial forms, which are then discussed and specified;

- approve specified forms of output.

Especially noteworthy is the development of the sketch of the visual form of output. First of all, for every type is determined the content of its three zones :

- a title or title page of the machine diagram, which presents once or partially on each page;

- column header (column names and numbering are on each page);

- the main subject (information) part.

The last zone is with rows of two types: specified and summary. Specified rows contain the data that is in the records of the input arrays. The details in the specified row should be from left to right in the following order:

- permanent;

- variable;

- total in amount. 


\section{Shkvir, I. Borshchuk}

Before entering details in the specified sequence, it is necessary to establish a hierarchy of crucial and quantitative and final details. It is essential to make the following: at the beginning the key details, which has the highest level in the hierarchy, then which has the next level, etc.

Talking about basic details, they are in the reverse order: at the beginning, the details with the lowest level of the hierarchy, followed by the next level details, and so on.
Example. The following details must be noted: department (K1), station (K2), plate number (K3), sum by plate number (P1), sum by district (P2), sum by department (P3). The hierarchy of key details and essentials will be as follows:

$$
\mathrm{K} 1 \rightarrow \mathrm{K} 2 \rightarrow \mathrm{K} 3 \text { and } \mathrm{P} 3 \rightarrow \mathrm{P} 2 \rightarrow \mathrm{P} 1 .
$$

Then, in accordance with the stated rule, the document with the results will take the form:

\begin{tabular}{|l|c|c|c|c|c|}
\hline Department & District & Number plate & Sum of number plate & $\begin{array}{c}\text { Sum of } \\
\text { district }\end{array}$ & $\begin{array}{c}\text { Sum of } \\
\text { department }\end{array}$ \\
\hline K1 & K2 & K3 & P1 & P2 & P3 \\
\hline
\end{tabular}

The summary lines contain the quantitative and total results for specific grouping characteristics, the results of the performed calculations. Estimated indicators (the amount for the districts, the amount for the department, etc.) are sometimes not in the column of machine diagrams, but in rows. Then the summary lines enter the totals indicating the results of the calculation for each detail. For example: "Summary for District 1", "Summary for District 2", "Summary for Department 1", "Summary for Department 2", etc. Often, text lines (such as "Together by ...", "Total," etc.) add to the summary lines.

During determining the content and form of the document takes into account its purpose, sphere, and features of use, frequency of receipt, etc. It is important to relate different performance metrics to determine whether you can combine them into one form or whether you need to form two or more similar forms at the same time. It is necessary to remember about the technical capabilities of the informational means of output, but also the features of the provided software tools for data preparation and output. For example, when designing video games, the informational capacity of the display screen, the number of lines per frame, and the number of characters per line are taken into account.

When processing information on the computer, all the outgoing documents are first formed on machine carriers and then displayed in the form of machine or video diagrams. In such materials, the resultant information is in two modes: regulatory and query. In the regular method, the machine diagrams are issued according to the plan following previously set terms. For example, payroll is made monthly, and the user can get it following clearly set dates.

The request mode ensures that the resulting information can be seen at all times. For example, querying the number of employees of an enterprise by staff category as of the current date, etc.

\section{Conclusions and perspectives of further research}

Therefore, the accountant, who will operate this system, should develop the informational documents, in particular, operational and documents with result information, as one of the components of the CIS-BO nonautomated database.Using the methods proposed in the article and acquainted with the peculiarities of designing informational documents and having a thorough knowledge of accounting processes of the company, only an accountant will be able to create effective forms of primary documents and documents with results, on which rational management decisions base. 
The specifics of designing informational documents of nonauthomated...

The subject of further research is the creation of a methodology for the design of rational document circulation, which is important for automated information processing at the enterprise.

\section{References}

1. Shkvir V., Borshchuk I. (2018). Methodology of construction accounting nomenclature codes of non-automatic informational base of computer accounting system. Economics, Entrepreneurship, Management, 5 (2), 51-58. https://doi.org/10.23939/ eem2018.02.051.

2. Shkvir, V. D., Zagorodniy, A. G.\& Vysochan, O. S. (2017). Informatsiini systemy I tekhnolohii v obliku ta audyti [Infirmation systems and technologies in accobnting and auditing: textbook], (4th ed, rev) [in Ukrainian].

3. Benko, M. M. (2010). Informatsiini systemy I tekhnolohii v bukhalterskomu obliku [Information systems and technologies in accjunting]. Kyiv: nats auction.-econ. Unt. [in Ukrainian].

4. Ivakhnenkov, S. V. (2010). Informatsiini tekhnolohii audytu ta vnutrishnohospodarskoho kontroliu $v$ koteksti svitovoi informatsii [Information technology of audit and internal control in the context of world information.] Zhytomyr: PE "Ruta" [in Ukrainian].

5. Ivakhnenkov, S. V. (2005). Kompiuternyi audyt: kontrolni metodyky i tekhnolohii [Computer audit: control technigues and technologies]. K: Knowledge [in Ukrainian].

6. Susidenko, V. T. (2016). Informatsiini systemy $i$ tekhnolohii [Information system and technologies]. Kyiv: Tsentr uchbovoi literatury [in Ukrainian].

7. Sytnyk V. F.,, Pysarevska T. A., Yeromina N. V. i Kraieva O. S. (2001). Osnovy informatsiinyh system [Basics of information systems: textbook], (2 edition, rev). K: KHEV [in Ukrainian].

8. Honcharuk Y. A., Marushko N. S, Lozovytskyi D. S. and Volyniak H. M. (2014). Informatsiini systemy $i$ tehnolohii $v$ obliku [Information systems and technologies in accounting: textbook]]. Lviv: Mahnoliia 2006 [in Ukrainian].

9. Zhuravleva I. V. \& Pasenko N. S. (2005). Informacionnyie sistemy $i$ tehnologii $v$ uchete [Information systems and technologies in accounting: textbook]. Х: ХНЭУ [in Russian]. 